\title{
Médiévales
}

Langues, Textes, Histoire

75 | automne 2018

Traductions du Moyen Âge

\section{Élisabeth LUSSET, Crime, châtiments et grâce dans les monastères au Moyen Âge (XII ${ }^{e}-\mathrm{XV}^{e}$ siècle)}

Turnhout, Brepols (« Disciplina Monastica », 12), 2017, 406 p.

\section{Megan Cassidy-Welch}

Traducteur : Alban Gautier

\section{(2) OpenEdition \\ Journals}

\section{Édition électronique}

URL : https://journals.openedition.org/medievales/9647

DOI : $10.4000 /$ medievales.9647

ISSN : $1777-5892$

\section{Éditeur}

Presses universitaires de Vincennes

\section{Édition imprimée}

Date de publication : 15 octobre 2018

Pagination : 257-259

ISBN : 978-2-84292-861-2

ISSN : 0751-2708

\section{Référence électronique}

Megan Cassidy-Welch, «Élisabeth Lusset, Crime, châtiments et grâce dans les monastères au Moyen Âge ( $x I^{e}-x v^{e}$ siècle) », Médiévales [En ligne], 75 | automne 2018, mis en ligne le 15 octobre 2018, consulté le 23 avril 2022. URL : http://journals.openedition.org/medievales/9647 ; DOI : https://doi.org/10.4000/ medievales.9647

\section{Ce document a été généré automatiquement le 23 avril 2022}

Tous droits réservés 


\section{Élisabeth LUSSET, Crime, châtiments et grâce dans les monastères au Moyen Âge (XII $-\mathrm{XV}^{e}$ siècle)}

Turnhout, Brepols (« Disciplina Monastica », 12), 2017, 406 p.

\section{Megan Cassidy-Welch}

Traduction : Alban Gautier

\section{RÉFÉRENCE}

Élisabeth LUSSET, Crime, châtiments et grâce dans les monastères au Moyen Âge (XII $-\mathrm{XV}$ siècle), Turnhout, Brepols (« Disciplina Monastica », 12), 2017, 406 p.

1 Cet excellent livre constitue un complément bienvenu à l'histoire sociale et culturelle du monachisme occidental au Moyen Âge. L'enquête et l'analyse d'Élisabeth Lusset portent sur une diversité de sources normatives et narratives se rapportant aux crimes commis par des moines, des moniales et des chanoines réguliers. En rassemblant une documentation dispersée, l'auteure apporte une contribution nouvelle à l'historiographie du crime et du châtiment au Moyen Âge, aux travaux sur le sens de la discipline et de la correction dans la vie religieuse, et à l'histoire institutionnelle du monachisme.

2 Le livre comprend six gros chapitres, encadrés par une introduction et une conclusion. Il inclut aussi trois appendices : une table des principales sources pour les différents ordres religieux, et deux copies de suppliques du $\mathrm{xv}^{\mathrm{e}}$ siècle adressées à la Pénitencerie apostolique par un chanoine régulier et par un cellérier bénédictin. D'utiles listes d'abréviations, un index nominum, un index rerum, des catalogues, des manuscrits et des sources imprimées, et enfin une bibliographie sélective, aident le lecteur à naviguer à travers l'ouvrage. 
3 Le propos principal d'Élisabeth Lusset est le suivant: la fonction de la justice ecclésiastique dans le cadre monastique n'était pas tant de punir que de corriger, «c'est-à-dire d'amender et de réformer le comportement des délinquants » (p. 327). Les motivations en résidaient peut-être moins dans une inquiétude à l'égard du crime religieux individuel et de ses conséquences possibles en termes de salut, que dans une volonté institutionnelle de limiter la portée des comportements criminels et de prévenir le scandale. Cela permettait de consolider l'autonomie institutionnelle en matière de justice, mais aussi d'aligner ces questions de discipline religieuse sur les structures épiscopales et pontificales avec lesquelles tous les établissements religieux y compris les cisterciens avec leur exemption de visite et leur chapitre généraldevaient coopérer.

4 Le premier chapitre fournit une vision synthétique des diverses corrections du crime en contexte monastique, à partir des documents produits par ces institutions. Le « chapitre des coulpes » impliquait une correction à la fois « privée » et « publique » : il reposait sur la confession et sur la réflexion individuelle, mais celles-ci se déroulaient en présence de la communauté, dont les membres faisaient office de témoins et de dénonciateurs. À Saint-Martin de Tournai par exemple, des circuli constitués des membres de la communauté sillonnaient le monastère à la recherche de délinquants. Ce chapitre étudie aussi le développement des régulations au sein des ordres réformés au $\mathrm{XII}^{\mathrm{e}}$ siècle et l'adoption du modèle du chapitre général dans de nombreux contextes au début du XIII ${ }^{\mathrm{e}}$ siècle. Ce modèle était articulé à des systèmes de visites (abbatiales et épiscopales) qui consacraient de grands efforts à s'assurer d'un maintien d'une bonne discipline au sein des établissements. Certes, il existait des différences entre les ordres en termes de régulations du comportement et de contrôle interne et externe mais, comme le montre bien Élisabeth Lusset, ils étaient tous influencés par les interventions pontificales en matière de discipline monastique. Celles-ci pouvaient prendre la forme d'ingérences directes, mais elles pouvaient aussi être l'effet de l'influence papale sur les hiérarchies ecclésiastiques et des revendications plus générales de juridiction suprême.

5 Le chapitre 2 traite des procédures d'enquête, de dénonciation et de grâce. La pratique de la dénonciation fournissait une information sur les crimes commis au sein d'une communauté religieuse : au cours $\mathrm{du}$ XIII ${ }^{\mathrm{e}}$ siècle, cette pratique fut progressivement absorbée par l'ordo inquisitionis. Ces points sont patiemment déduits de deux études de cas. La première porte sur un cas de violence connu par une enquête épiscopale de 1281 au prieuré de Wootton Wowen en Angleterre; la seconde concerne un complot ourdi par un moine clunisien afin de diffamer son prieur, à Savigny en 1332. Ces deux affaires sont soigneusement contextualisées afin de mettre en lumière le pouvoir de la parole et des témoins dans les processus inquisitoires, et la nature de l'autorité attestante. Le chapitre se termine par un survol des pétitions adressées à la curie pontificale par des moines, des moniales ou des chanoines.

6 Le chapitre 3 propose une typologie des crimes et des circonstances dans lesquelles ils ont été commis. L'auteure note la prépondérance des crimes de violence entre le milieu $\mathrm{du} \mathrm{XIII}^{\mathrm{e}}$ et le milieu du XVI $\mathrm{XI}^{\mathrm{e}}$ siècle; l'homicide et l'apostasie (ou plus généralement la fuite) restent aussi très présents dans la documentation. Le lieu des crimes est étudié à l'intérieur ou à l'extérieur de la clôture monastique - ainsi que leur temporalité - ils se déroulent surtout la nuit. La plupart des crimes étaient commis par des individus plutôt que par des groupes, même s'il existe de nombreux exemples de crimes collectifs. Les sanctions ecclésiastiques contre le port d'armes par des religieux 
réguliers ne semblent guère avoir eu d'effet sur certains moines criminels : plus de $35 \%$ des suppliques adressées à la Pénitencerie font mention d'armes.

7 Le chapitre 4 est consacré aux motivations du crime. Ici la documentation, en particulier celle de la Pénitencerie apostolique, s'avère très loquace. Élisabeth Lusset estime que ces récits parfois très détaillés ne peuvent pas être pris au pied de la lettre, car ils ont été faits dans le but d'obtenir la bienveillance de la curie. Ils nous fournissent cependant un aperçu de la grande variété de torts subis par les individus, qui pouvaient les pousser à recourir à la violence, et des types de justifications que les pétitionnaires incluaient dans le compte rendu de leurs méfaits. Les chroniques contiennent également des exemples de querelles et de violences : là aussi, les logiques narratives doivent être prises en compte, mais ces textes nous aident quand même à mieux comprendre ce qui était perçu, dans la culture du temps, comme des comportements acceptables ou inacceptables. Colère, ivresse, animosité personnelle, haine, querelles d'autorité ou de partage de biens communs, sont parmi les causes les plus fréquentes. Il est intéressant de noter que les questions de gouvernement provoquaient des conflits divers: entre groupes ethniques au sein de certaines communautés, entre groupes d'âge dans d'autres. Des moines pouvaient ne pas apprécier les marques de faveur prodiguées par l'abbé à certains membres de la communauté, tandis que dans d'autres cas les abbés étaient attaqués pour leur application trop rigide de la discipline. L'exemple bien connu des frères lais cisterciens est ici discuté, et l'auteure explique bien comment ce groupe était représenté dans les statuts cisterciens. Elle développe aussi la question de la représentation des réformateurs monastiques comme victimes de crimes.

8 Le chapitre 5 porte sur les châtiments. Élisabeth Lusset retrace ici l'histoire de la distinction entre transgressions majeures et mineures, et celle des diverses formes d'inclusion et d'exclusion disciplinaires: elle montre ainsi que des châtiments très variés ont existé tout au long du Moyen Âge. Le Moyen Âge central a vu le développement de modes plus systématiques de correction institutionnelle: ainsi l'utilisation plus répandue de l'emprisonnement a pu fonctionner au côté de l'excommunication ou de l'expulsion, généralement dans le but de protéger les établissements et leur réputation.

9 Le dernier chapitre s'intéresse à la grâce en se démarquant d'une historiographie ancienne, pour laquelle celle-ci était le signe d'un certain laxisme au sein des communautés. Élisabeth Lusset se concentre au contraire sur les moyens par lesquels la grâce était accordée, et étudie les pratiques d'absolution, de réconciliation, de réhabilitation et de réparation comme des aspects de la pratique institutionnelle et hiérarchique. La grâce pontificale fait l'objet d'une section intéressante sur la réintégration dans les monastères de moines bénéficiaires de lettres de grâce de la Pénitencerie apostolique. Le livre se conclut sur une vue d'ensemble des évolutions du crime et des châtiments en contexte monastique tout au long du Moyen Âge.

10 Il s'agit donc d'un livre tout à fait novateur, qui replace le crime et le châtiment monastiques au sein de contextes institutionnels, ecclésiastiques, sociaux et culturels variés. Il fait habilement dialoguer documents de la pratique et sources narratives, tout en se confrontant à plusieurs traditions historiographiques. L'ouvrage est impressionnant par son ampleur comme par sa profondeur : l'étude d'ordres religieux aussi divers sur une période d'environ trois cents ans est une tâche pour le moins ambitieuse. Élisabeth Lusset a pourtant réussi à la fois à lire les sources avec soin et à 
esquisser une vue générale de la place qu'occupaient le crime et le châtiment dans les communautés religieuses médiévales. Ce livre aura un impact durable sur l'histoire de la vie monastique au Moyen Âge et des défis auxquels elle était confrontée.

\section{AUTEURS}

\section{MEGAN CASSIDY-WELCH}

School of Historical and Philosophical Inquiry, University of Queensland 